\title{
Autogenous Bone Grafts versue Metal Cage with Allo- genic Bone Grafts for Post-Corpectomy Anterior Column Reconstruction in Patients with Infectious Spondylitis
}

\author{
Jae-Ryong Cha, Il-Yeong Hwang, Sun-Hwan Kwon, Hee-Yoon Chung \\ Department of Orthopedic Surgery, Ulsan University Hospital, University of Ulsan College of Medicine, Ulsan, Korea
}

Objective : To evaluate and compare the clinical and radiographic features of 25 patients with infectious spondylitis treated with anterior debridement and reconstruction using autogenous bone grafts vs. a metal cage with allogenic bone grafts.

Methods : The study analyzed 25 patients diagnosed with infectious thoracolumbar spondylitis who underwent anterior radical debridement and reconstruction. Autogenous bone grafts were used in 13 patients (group 1), and a metal cage with allogenic bone grafts was used in 12 patients (group 2). Clinical outcomes were assessed by the visual analogue scale (VAS) scores and neurological status. Additionally, the serological results and the radiographic results using the sagittal Cobb angle were compared. Fusion was evaluated by computed tomography (CT) imaging at 24 months postoperatively.

Results : Both groups showed a significant decrease in the postoperative mean VAS scores; however, only, group 1 patients showed a significantly higher VAS score than group 2 patients, 1 month postoperatively $(p=0.002)$. The postoperative neurological status significantly improved. Elevated C-reactive protein levels and erythrocyte sedimentation rate values returned to normal limits at the 2-year follow-up without recurrent infection. No significant intergroup difference was observed in Cobb angle. Bony fusion was confirmed in all patients at CT 24 months postoperatively.

Conclusion : Although the use of a metal cage with allogenic bone grafts for anterior column reconstruction remains controversial, our results suggest that it can be considered as an effective treatment of option for anterior column reconstruction in patients with infectious spondylitis.

Key Words : Spine $\cdot$ Infection $\cdot$ Instrumentation $\cdot$ Bone $\cdot$ Titanium.

\section{INTRODUCTION}

Management of spinal infections is challenging owing to their unclear initial presentation, varied manifestations, and complex mechanisms of progression ${ }^{1}$. The incidence rate of spinal infections is low (2.4 cases per 100000 persons); however, the disease course varies between mild and curable infections and severe infections causing chronic pain, weakness, paralysis, sepsis, and even death despite antibiotic and surgical treatment $t^{4,8)}$.

- Received : May 28, 2019 •Revised : July 15, 2019 •Accepted : August 13, 2019

- Address for reprints : II-Yeong Hwang

Department of Orthopedic Surgery, Ulsan University Hospital, University of Ulsan College of Medicine, 877 Bangeojinsunhwando-ro, Dong-gu, Ulsan 44055, Korea Tel : +82-52-250-7129, Fax : +82-52-235-2823, E-mail : yebben10@naver.com, ORCID : https://orcid.org/0000-0002-6143-4633 
Appropriate antibiotic treatment is essential for successful nonsurgical treatment. Criteria for surgical intervention are as follows : disease refractory to conservative management, spinal cord compression causing neurological deficit, progressive instability secondary to significant bony and soft tissue destruction, and chronic infection-induced severe scoliosis or kyphosis ${ }^{14,15}$.

Spinal infections usually affect the vertebral body; thus, an anterior surgical approach is commonly recommended to enable debridement of the lesion and vertebral column reconstruction using autogenous bone grafts or a metal cage ${ }^{2}$. Several biological and mechanical spacers such as allografts, autografts, and metal cages are used for post-corpectomy anterior column reconstruction. To date, reconstruction using a metal cage with allogenic bone grafts after radical debridement of the lesion is controversial ${ }^{233}$.

However, autogenous bone grafts are associated with donor site morbidity such as postoperative pain. Thus, several recent reports have described vertebral osteomyelitis treated with anterior reconstruction using a metal cage with allogenic bone grafts. These results show that the use of metal cages did not adversely affect the clinical and radiological outcomes in these patients. However, these results were not reported by casecontrol studies ${ }^{9,21,25,26)}$. Therefore, this study evaluated and compared the clinical and radiographic outcomes in $17 \mathrm{pa}-$ tients with infectious spondylitis who underwent anterior debridement and reconstruction using either autogenous bone grafts or a metal cage with allogenic bone grafts.

\section{MATERIALS AND METHODS}

This study was approved by Institutional Review Board of Ulsan University Hospital (2018-09-032).

\section{Patients}

This study included 25 patients diagnosed with infectious thoracolumbar spondylitis who underwent anterior radical debridement and reconstruction using either autogenous bone grafts or a metal cage with allogenic bone grafts at the hospital where this study was performed between February 2006 and January 2017. All patients were diagnosed with infectious spondylitis using magnetic resonance imaging (MRI), and additional laboratory tests were performed.
Between February 2006 and June 2012, autogenous bone graft was used for all patients. After then, all patients were treated with a metal cage with allogenic bone graft, because metal cage with allogenic bone graft was reported to be successful ${ }^{9,21,25,26)}$.

Autogenous bone grafts were used in 13 patients (group 1) and a metal cage with allogenic bone grafts in 12 patients (group 2). infectious spondylitis was diagnosed based on clinical examination (positive physical or neurological symptoms), laboratory findings (elevated erythrocyte sedimentation rate [ESR] and C-reactive protein [CRP] values), and radiographic and MRI findings. All 25 patients were followed-up for at least 24 months.

\section{Assessment of variables}

Patient's medical records including admission, emergency department, and inpatient progress notes, surgical and radiological reports, microbiological laboratory results, and discharge summaries were reviewed.

Clinical findings were assessed by instructing patients to qualify their pain on a visual analogue scale (VAS) using a scale of $0-10$ ( 0 , no pain; 10 , worst possible pain) preoperatively, as well as 1-, 12, and 24 months postoperatively. The severity of the neurological status was assessed using the Frankel scale preoperatively, as well as 1-, 12, and 24 months postoperatively (Table 1) $)^{6,12)}$.

Laboratory tests included estimation of ESR and CRP values preoperatively, as well as 1-, 12, and 24 months postoperatively.

Radiographic examination was performed to compare the correction in the sagittal Cobb angle. The Cobb angle was defined as the angle between the superior endplate of the vertebra above the level of instrumentation and the inferior end-

Table 1. The Frankel scale for spinal cord injury that classifies the extent of the neurological/functional deficit into five grades ${ }^{6)}$

\begin{tabular}{lll}
\hline \multicolumn{2}{l}{ Grade } & \multicolumn{1}{c}{ Description } \\
\hline A & Complete & No motor or sensory function below level of lesion \\
B & Sensory only & $\begin{array}{l}\text { No motor function, but some sensation preserved } \\
\text { below level of lesion }\end{array}$ \\
C & Motor useless & Some motor function without practical application \\
D & Motor useful & Useful motor function below level of lesion \\
E & Recovery & $\begin{array}{l}\text { Normal motor and sensory function, may have } \\
\text { reflex abnormalities }\end{array}$ \\
\hline
\end{tabular}


plate of the vertebra below this level (Fig. 1). The Cobb angle was measured preoperatively, postoperatively, 12 months

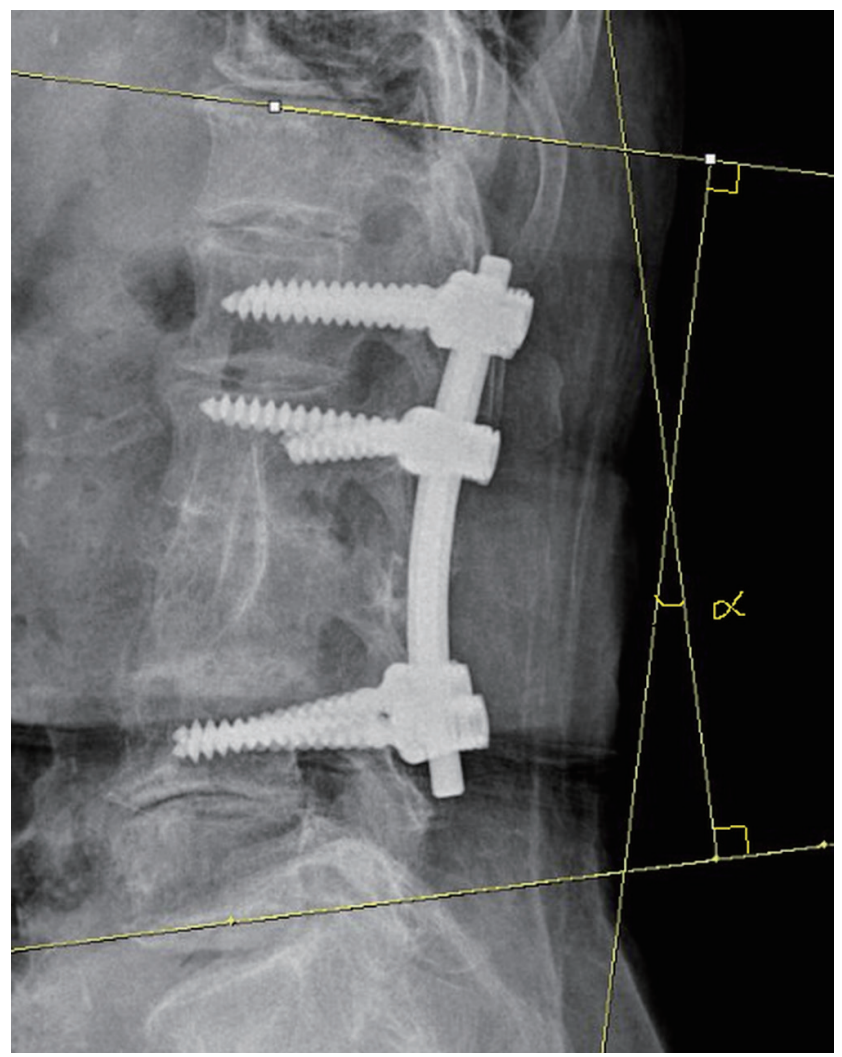

Fig. 1. Image showing measurement of the Cobb angle. postoperatively and, 24 months postoperatively. The difference between the preoperative Cobb angle and the 2-year postoperative Cobb angle was defined as the Cobb angle change. Fusion was evaluated by computed tomography (CT) imaging at 24 months postoperatively. Grade of 1 or 2 on CT imaging was defined as a successful bony fusion by using CTbased classification (grade I : complete fusion, implies cortical union of the allograft and central trabecular continuity; grade II : partial fusion, implies cortical union of the structural allograft with partial trabecular incorporation; grade III : unipolar pseudarthrosis, denotes superior or inferior cortical non-union of the central allograft with partial trabecular discontinuity centrally; and grade IV : bipolar pseudarthrosis, suggests both superior and inferior cortical nonunion with a complete lack of central trabecular continuity) ${ }^{22}$.

\section{Statistical analysis}

The chi-square test and Fisher's exact test were used for categorical data analysis such as intergroup comparison of sex, the Frankel scale, and bone union, and the Mann-Whitney U test was used for mean comparison such as intergroup comparison of age, mean number of infected vertebral segments, mean number of segments of posterior instrumented vertebrae, mean number of segments of anterior instrumented vertebrae, VAS, ESR, CRP values, and the sagittal Cobb angle.

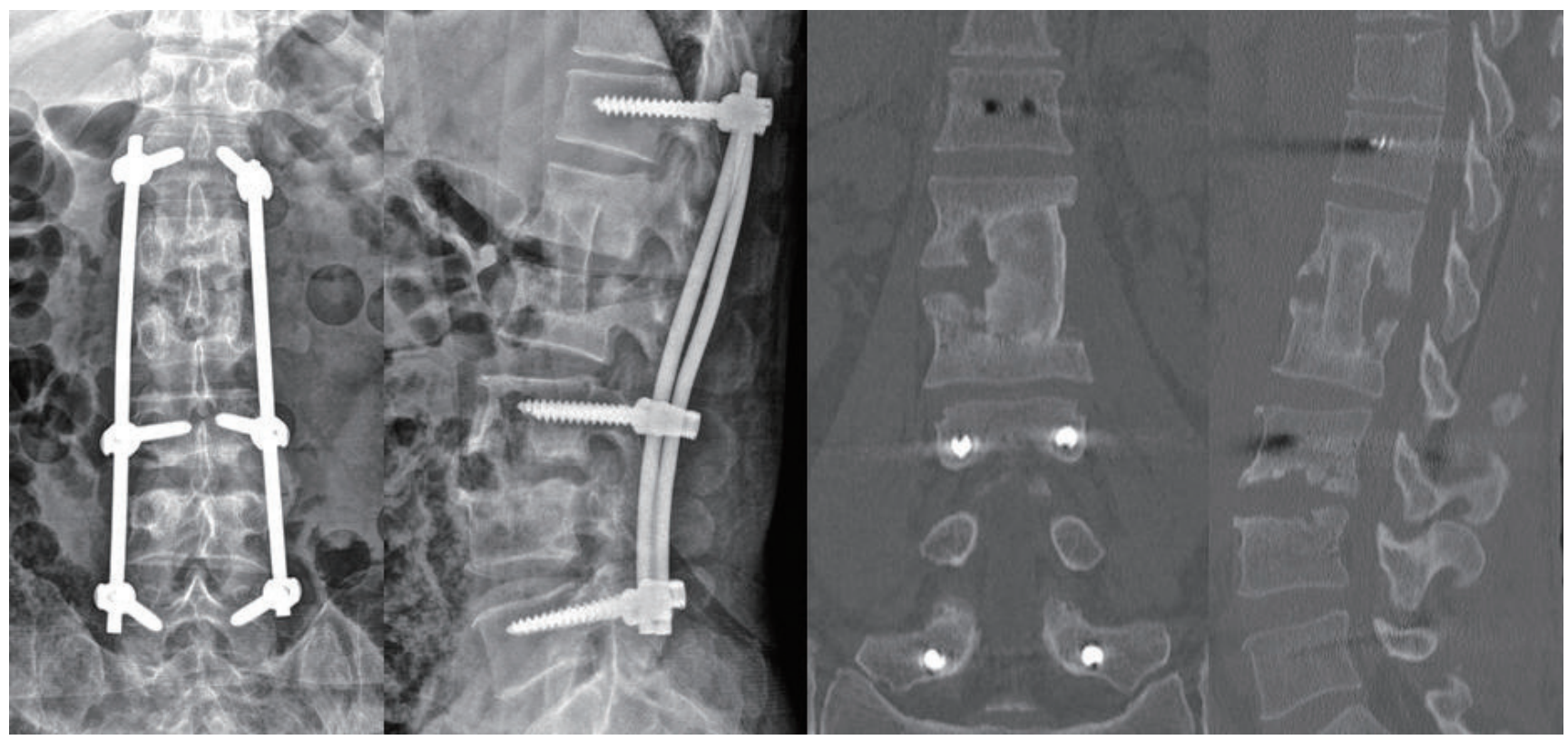

Fig. 2. Image showing anterior radical debridement and autogenous bone graft harvested from the patient's left iliac bone. Supplemental posterior pedicle screw instrumentation can be observed to treat infectious spondylitis and correct the kyphotic deformity. 
The SPSS software version 21.0 (SPSS Inc., Chicago, IL, USA) was used for data analysis. A $p$-value $<0.05$ was considered statistically significant.

\section{Surgical technique}

All patients underwent anterior debridement and reconstruction using the anterior transthoracic or retroperitoneal approach. All operations were performed by a single spine specialist (J.R.C.). All operations were performed under general anesthesia with endotracheal intubation. Vital signs including blood pressure, heart rhythm, and pulse oxygenation levels were monitored by anesthesiologists in all patients. Radical debridement and removal of all infected tissue was performed with complete decompression of the spinal cord. Smears and cultures were obtained, and the surgical field was copiously irrigated with normal saline solution. After radical debridement, the length of the defect was measured, and a tricortical iliac bone block and a cancellous bone graft (Fig. 2) or a metal cage (The VLIFT ${ }^{\circledast}$ Vertebral Body Replacement System, titanium; Stryker, Kalamazoo, MI, USA) with an allogenic bone graft (Fig. 3) was inserted into the space between the normal vertebrae. The wound was closed after drain insertion. All patients wore a rigid orthosis for at least 3 months postoperatively and received systemic antibiotic treatment

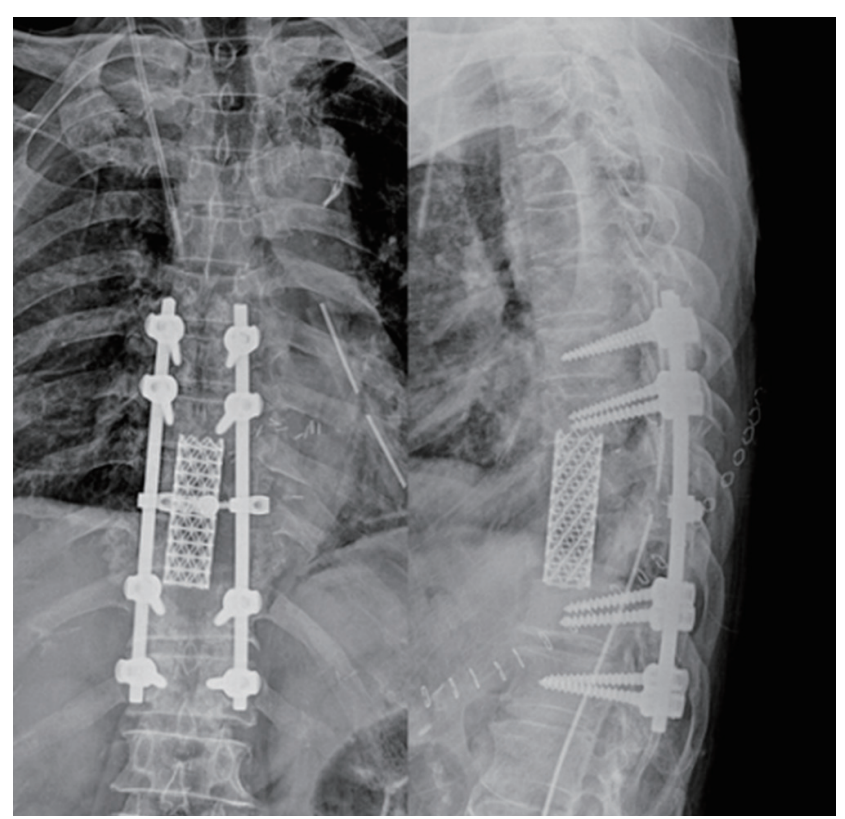

Fig. 3. Image showing anterior radical debridement and metal cage implantation combined with posterior pedicle screw instrumentation to treat infectious spondylitis and to correct the kyphotic deformity. based on antibiotic sensitivity studies for identified pathogens. Intravenous antibiotic administration was continued for at least 6 weeks postoperatively. Broad-spectrum antibiotics were administered to patients with negative culture results.

\section{RESULTS}

\section{Demographic data}

The mean age of groups 1 and 2 was $73.5 \pm 15.9$ and $73.4 \pm 8.7$ years, respectively, and no significant intergroup difference was observed with respect to age $(p=0.837)$. In group 1 , there were five men (38.5\%) and eight women (61.5\%), and in group 2, there were six men $(50.0 \%)$ and six women (50.0\%). There was no significant difference in sex between the groups $(p=0.561)$. The mean number of infected vertebral segments in group 1 was $1.2 \pm 0.6$ and in group 2 was $1.3 \pm 0.5$, and no significant intergroup difference was observed with respect to this parameter $(p=1.000)$. The mean number of segments of posterior instrumented vertebrae in group 1 was $3.1 \pm 1.0$ and in group 2 was 3.3 \pm 0.5 , and no significant intergroup difference was observed with respect to this parameter $(p=1.000)$. The mean number of segments of anterior instrumented vertebrae in group 1 was 1.3 \pm 0.6 and in group 2 was $1.2 \pm 0.4$, and no significant intergroup difference was observed with respect to this parameter $(p=0.650)$. The causative bacteria were isolated in 19 of 25 (76.0\%) biopsy cultures, either pre- or intraoperatively. Staphylococcus aureus was the causative pathogen in 13 of the 25 $(52.0 \%)$ patients investigated in this study (six were oxacillinsensitive strains and seven were oxacillin-resistant strains). Pseudomonas aeruginosa, Escherichia coli, and Enterococcus faecalis infections occurred in six patients (Table 2).

\section{Clinical results}

Both groups showed a significant reduction in severe back pain related to infectious spondylitis. In group 1, back pain decreased from a mean VAS score of $8.13 \pm 1.33$ preoperatively to a VAS score of $5.00 \pm 0.711$ month postoperatively, to a VAS score of $1.78 \pm 0.83$ at the 12 months postoperatively, and to a VAS score of $1.67 \pm 0.71$ at the 24 months postoperatively. In group 2, back pain decreased from a mean VAS score of $7.89 \pm$ 0.93 preoperatively to a VAS score of $3.56 \pm 0.731$ month postoperatively, to a VAS score of $1.56 \pm 0.53$ at the 12 months postoperatively, and to a VAS score of $1.62 \pm 0.74$ at the 24 months 
postoperatively. No significant intergroup difference was observed preoperatively ( $p=0.690$ ), at the 12 months postoperatively $(p=0.666)$, and at the 24 months postoperatively ( $p=0.878$ ). However, group 1 patients showed a significantly higher VAS score than group 2 patients 1 month postoperatively ( $p=0.002$ ) (Table 3, Fig. 4).

Neurological deficits improved in both groups. The Frankel scale was compared between the groups preoperatively

Table 2. Patients' demographic data

\begin{tabular}{|c|c|c|c|c|c|c|}
\hline Case No. & Age (years) & Gender & Infection level & Anterior IL & Posterior IL & Pathogen \\
\hline \multicolumn{7}{|c|}{ Autogenous bone graft (group 1) } \\
\hline 1 & 90 & F & $\mathrm{L} 2, \mathrm{~L} 3$ & L2-L3 & L1-L4 & No growth \\
\hline 2 & 79 & $\mathrm{~F}$ & $\mathrm{~L} 2, \mathrm{~L} 3$ & $\mathrm{~L} 2-\mathrm{L} 4$ & $\mathrm{~L} 2-\mathrm{L} 4$ & OSSA \\
\hline 3 & 80 & $\mathrm{~F}$ & $\llcorner 3, L 4$ & L3-L4 & $\mathrm{L} 2-\mathrm{L} 5$ & OSSA \\
\hline 4 & 62 & $\mathrm{~F}$ & $\mathrm{~T} 6, \mathrm{~T} 7$ & T6-T7 & T6-T7 & PA \\
\hline 5 & 33 & M & $\mathrm{L} 2, \mathrm{~L} 3$ & $\mathrm{~L} 2-\mathrm{L} 3$ & L1- L4 & No growth \\
\hline 6 & 88 & $\mathrm{~F}$ & $\mathrm{~L} 3, \mathrm{~L} 4$ & L3-L4 & L2-S1 & ORSA \\
\hline 7 & 80 & $\mathrm{~F}$ & $\mathrm{~L} 2, \mathrm{~L} 3$ & $\mathrm{~L} 2-\mathrm{L} 3$ & L1-L4 & PA \\
\hline 8 & 56 & M & $\mathrm{L1}, \mathrm{L} 2, \mathrm{~L} 3, \mathrm{~L} 4$ & L1-L4 & T12-L5 & ORSA \\
\hline 9 & 74 & M & L3, L4 & L3-L4 & L2-L5 & $\mathrm{EC}$ \\
\hline 10 & 90 & $F$ & $\mathrm{~L} 2, \mathrm{~L} 3$ & L2-L3 & L1-L4 & OSSA \\
\hline 11 & 75 & M & L3, L4, L5 & L3-L5 & $\mathrm{L} 2-\mathrm{S} 1$ & ORSA \\
\hline 12 & 67 & M & $\llcorner 4, L 5$ & L4-L5 & L3-S1 & No growth \\
\hline 13 & 81 & $F$ & $\mathrm{~L} 3, \mathrm{~L} 4$ & L3-L4 & L2-L5 & OSSA \\
\hline \multicolumn{7}{|c|}{ Metal cage with allogenic bone graft (group 2) } \\
\hline 14 & 83 & M & L3, L4, L5 & $\llcorner 4-\llcorner 5$ & L2--S1 & OSSA \\
\hline 15 & 85 & $F$ & $\llcorner 4, L 5$ & $\llcorner 4-\llcorner 5$ & L3-S1 & $\mathrm{EF}$ \\
\hline 16 & 59 & $F$ & $\mathrm{~T} 6, \mathrm{~T} 7$ & T6-T7 & T5-T8 & EC \\
\hline 17 & 82 & M & T9, T10 & T9-T10 & T8-T11 & ORSA \\
\hline 18 & 73 & $F$ & T12, L1, L2 & $\mathrm{L} 1-\mathrm{L} 2$ & T11vL3 & No growth \\
\hline 19 & 78 & M & $\llcorner 3, L 4$ & $\mathrm{L} 3-\mathrm{L} 4$ & $\mathrm{~L} 2-\mathrm{L} 5$ & EF \\
\hline 20 & 72 & $F$ & T6, T7, T8 & T6-T8 & T5-T9 & ORSA \\
\hline 21 & 76 & M & $\mathrm{L} 2, \mathrm{~L} 3$ & L2-L3 & L1-L4 & No growth \\
\hline 22 & 71 & $F$ & $\mathrm{~L} 2, \mathrm{~L} 3$ & L2vL3 & L1-L4 & ORSA \\
\hline 23 & 70 & $F$ & $\llcorner 3,\llcorner 4$ & L3-L4 & L2-L5 & OSSA \\
\hline 24 & 75 & M & L3, L4, L5 & L3-L5 & L2-S1 & No growth \\
\hline 25 & 57 & M & $\mathrm{L} 3, \mathrm{~L} 4$ & L3-L4 & $\mathrm{L} 2-\mathrm{L} 5$ & ORSA \\
\hline
\end{tabular}

IL : instrumented level, F : female, L : lumbar spine, OSSA : Oxacillin-sensitive Staphylococcus aureus, T: thoracic spine, PA : Pseudomonas aeruginosa, M : male, ORSA : Oxacillin-resistant Staphylococcus aureus, EF : Enterococcus faecalis, EC : Escherichia coli

Table 3. Comparison of clinical outcomes before surgery and after surgery - VAS score

\begin{tabular}{lccc}
\hline & Group 1 & Group 2 & $p$-value \\
\hline Preoperatively & $8.13 \pm 1.33$ & $7.89 \pm 0.93$ & 0.690 \\
1 month postoperatively & $5.00 \pm 0.71$ & $3.56 \pm 0.73$ & $0.002^{*}$ \\
12 months postoperatively & $1.78 \pm 0.83$ & $1.56 \pm 0.53$ & 0.666 \\
24 months postoperatively & $1.67 \pm 0.71$ & $1.62 \pm 0.74$ & 0.878 \\
\hline
\end{tabular}

Values are presented as mean \pm standard deviation. *Statistical significance. VAS : visual analog scale 


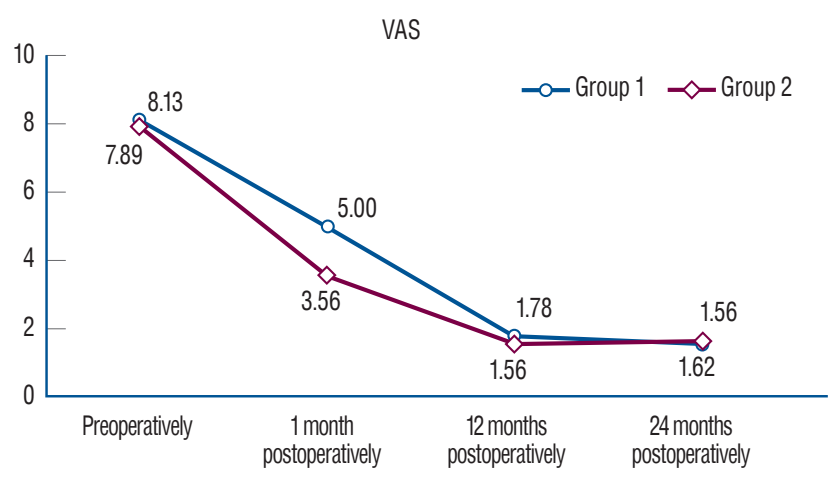

Fig. 4. This is a graph showing the change of VAS after operation. In both groups, VAS was decreased after operation, but VAS of group 1 was significantly higher than group 2 at 1 month postoperatively. VAS : visual analogue scale.
( $p=0.543), 1$ month postoperatively $(p=0.863)$, at the 12 months ostoperatively ( $p=0.821$ ), and at the 24 months postoperatively ( $p=0.821)$. No significant intergroup difference was observed in the Frankel scale. No postoperative neurological deterioration was observed (Table 4).

\section{Laboratory findings}

Elevated CRP and ESR values returned to within normal limits at the 24 months postoperatively in both groups. No recurrent infection occurred (Table 5, Fig. 5A and B).

\section{Radiographic results}

No significant intergroup difference was observed preoper-

Table 4. Comparison of clinical outcomes before surgery and after surgery - Frankel scale

\begin{tabular}{|c|c|c|c|c|}
\hline Frankel scale & Preoperative & $\begin{array}{c}1 \text { month } \\
\text { postoperatively }\end{array}$ & $\begin{array}{c}12 \text { months } \\
\text { postoperatively }\end{array}$ & $\begin{array}{c}24 \text { months } \\
\text { postoperatively }\end{array}$ \\
\hline \multicolumn{5}{|l|}{ Group 1} \\
\hline A & $0(0)$ & $0(0)$ & $0(0)$ & $0(0)$ \\
\hline B & $5(38.5)$ & $2(15.4)$ & $0(0)$ & $0(0)$ \\
\hline C & $6(46.2)$ & $4(30.8)$ & $0(0)$ & $0(0)$ \\
\hline D & $2(15.4)$ & $7(53.8)$ & $6(46.2)$ & $6(46.2)$ \\
\hline E & $0(0)$ & $0(0)$ & $7(53.8)$ & $7(53.8)$ \\
\hline \multicolumn{5}{|l|}{ Group 2} \\
\hline A & $0(0)$ & $0(0)$ & $0(0)$ & $0(0)$ \\
\hline B & $3(25.0)$ & $1(8.3)$ & $0(0)$ & $0(0)$ \\
\hline C & $5(41.7)$ & $4(33.3)$ & $0(0)$ & $0(0)$ \\
\hline D & $4(33.3)$ & $7(58.3)$ & $5(41.7)$ & $5(41.7)$ \\
\hline$E$ & $0(0)$ & $0(0)$ & $7(58.3)$ & $7(58.3)$ \\
\hline$p$-value & 0.543 & 0.863 & 0.821 & 0.821 \\
\hline
\end{tabular}

Values are presented as number (\%). Frankel scale : $A=$ complete paralysis; $B=$ sensory function only below the injury level; $C=$ incomplete motor function below injury level; $\mathrm{D}=$ fair to good motor function below injury level; $E$ = normal function

Table 5. Comparison of laboratory findings before surgery and after surgery

\begin{tabular}{lccc}
\hline & Group 1 & Group 2 & $p$-value \\
\hline Preoperative ESR & $77.33 \pm 27.11$ & $60.44 \pm 26.28$ & 0.541 \\
1 month postoperative ESR & $45.00 \pm 34.41$ & $33.77 \pm 23.66$ & 0.743 \\
12 months postoperative ESR & $21.78 \pm 23.93$ & $20.56 \pm 10.86$ & 0.606 \\
24 months postoperative ESR & $21.00 \pm 23.99$ & $20.00 \pm 10.90$ & 0.541 \\
Preoperative CRP & $9.60 \pm 5.63$ & $11.50 \pm 11.03$ & 0.888 \\
1 month postoperative CRP & $0.70 \pm 039$ & $1.82 \pm 2.10$ & 0.370 \\
12 months postoperative CRP & $0.44 \pm 0.75$ & $0.45 \pm 0.63$ & 0.743 \\
24 months postoperative CRP & $0.41 \pm 0.72$ & $0.41 \pm 0.58$ & 0.713 \\
\hline
\end{tabular}

Values are presented as mean \pm standard deviation. ESR : erythrocyte sedimentation rate, CRP : C-reactive protein 
atively ( $p=0.936)$, at postoperatively $(0.810)$ at the 12 months postoperatively $(p=1.000)$, and at the 24 months postoperatively ( $p=0.769$ ) in Cobb angle. There was no significant difference in Cobb angle change between group 1 (4.17 \pm 7.93$)$ and group 2 (4.55 \pm 8.67$)(p=0.574)$ (Table 6, Fig. 5C).

Bony union was confirmed in all patients (25 patients, 100\%) at CT 24 months postoperatively. Group 1 had 12 patient in grade 1 and one patient in grade 2 and, group 2 had 10 patients in grade 1 and two patients in grade 2, but no statistically significant difference $(p=0.593)$.

\section{DISCUSSION}

Patients with infectious spondylitis are treated with radical debridement followed by anterior column reconstruction us-

(A)
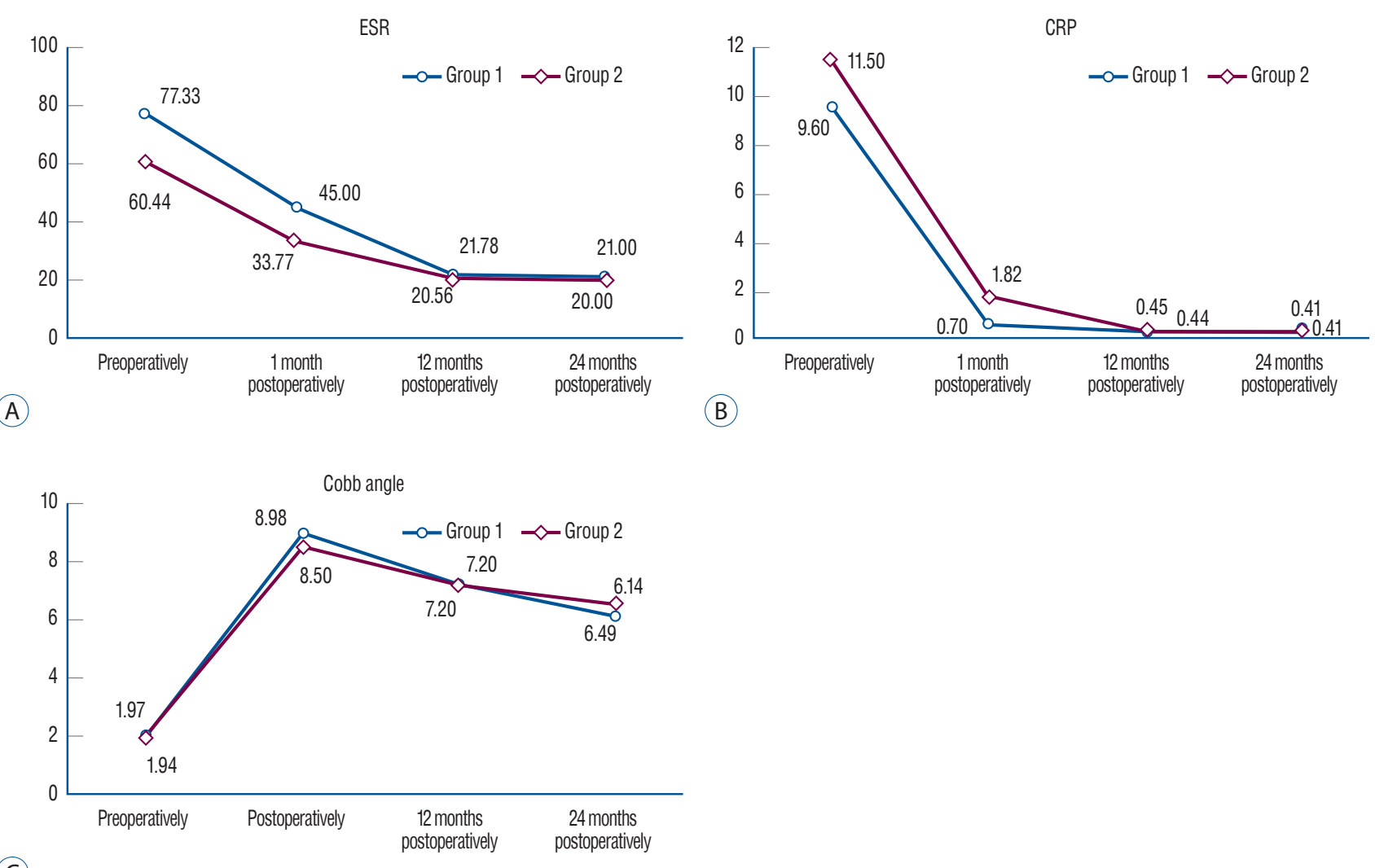

(C)

Fig. 5. These are graphs showing the change of ESR (A), CRP (B), and Cobb angle (C) after operation. There were no significant difference between the two groups. ESR : erythrocyte sedimentation rate, $\mathrm{CRP}: \mathrm{C}$-reactive protein.

Table 6. Comparison of radiographic findings before surgery and after surgery

\begin{tabular}{llcc}
\hline Cobb angle & Group 1 & Group 2 & $p$-value \\
\hline Preoperatively & $1.97 \pm 13.67$ & $1.94 \pm 19.55$ & 0.936 \\
Postoperatively & $8.98 \pm 8.71$ & $8.50 \pm 16.13$ & 0.810 \\
12 months postoperatively & $7.20 \pm 8.83$ & $7.20 \pm 15.22$ & 1.000 \\
24 months postoperatively & $6.14 \pm 9.60$ & $6.49 \pm 15.57$ & 0.769 \\
Cobb angle change* & $4.17 \pm 7.93$ & $4.55 \pm 8.67$ & 0.574 \\
\hline
\end{tabular}

Values are presented as mean \pm standard deviation. ${ }^{*} \mathrm{Cobb}$ angle change : the difference between the preoperative Cobb angle and the 24 months postoperative Cobb angle 
ing various biological and mechanical spacers, including autografts, allografts, and metal cages ${ }^{23}$. The defect created after debridement is commonly repaired using autogenous bone grafts from the fibula or the iliac crest. However, this procedure is associated with an approximately $25 \%$ increase in chronic morbidity $7,10,17,18,20)$. Allogenic bone grafts score over autogenous grafts in that they obviate the need for a donor sites, eliminate harvest site-related postoperative pain, and reduce added costs. However, the risk of allograft-related infection/disease transmission cannot be ignored. The use of metal cages for vertebral reconstruction and stabilization after debridement of an infected site is controversial, and few smallscale retrospective cohort studies have reported such cases. Recent studies have reported stability, safety, and low recurrence rates associated with the use of metal cages to treat spinal infections ${ }^{7,11,16,19)}$. An observational cohort study was performed across five tertiary care Korean hospitals. The study enrolled 153 patients with spinal infection who required surgical treatment. Among these patients, 94 (61.4\%) underwent non-instrumented surgery and 59 (38.6\%) underwent instrumented surgery. The results showed that spinal instrumentation did not adversely affect clinical outcomes ${ }^{13)}$. Several recent reports describe patients with vertebral osteomyelitis treated with anterior reconstruction using metal cages with allogenic bone grafts. These studies showed that using metal cages did not adversely affect the clinical and/or radiological outcomes; however, these studies were not case-control studies ${ }^{9,21,25,26}$. Therefore, this study analyzed several parameters to compare between the use of autogenous bone grafts and metal cages with allogenic bone grafts in patients undergoing anterior reconstruction.

The patients enrolled in this study underwent anterior radical debridement and corpectomy. Autogenous bone grafts were initially used for reconstruction following the corpectomy. However, with a growing number of studies showing that the use of metal cages was not associated with adverse results, metal cages with allogenic bone grafts were introduced for reconstruction to eliminate harvest-site pain associated with autogenous bone grafts. Among the 25 patients enrolled in this study, autogenous bone grafts were used in 13 (group 1), and a metal cage with allogenic bone grafts was used in 12 patients (group 2), and intergroup comparisons were performed with respect to several parameters.

Clinical findings were assessed using the VAS and Frankel scales. Patients from both groups had decreased back pain based on VAS scores, and no significant intergroup difference was observed at the 1-year and 2-year follow-up postoperatively. However, group 1 patients showed a significantly higher VAS score than group 2 patients, 1 month postoperatively, which could be attributed to bone harvest site pain in the former group. In this study, the iliac crest was used to obtain bone grafts. Postoperative pain and harvest-site infection, prolonged operation time, and increased bleeding are known complications of autogenous iliac crest bone grafting ${ }^{3}$. Younger and Chapman ${ }^{24)}$ reported a harvest site morbidity rate of $8 \%$ associated with autogenous iliac crest bone grafting, and Fernyhough et al. ${ }^{5)}$ reported a morbidity rate $>30 \%$ associated with an incorrect harvest site incision. Metal cages with allogenic bone grafts have advantage over the harvest-site complications compared to autogenous bone grafts.

All patients in this study showed improved postoperative neurological function and ESR and CRP values. No significant intergroup difference was observed in radiographic parameters.

The limitations of this study are as follows : 1) this was a small-scale study that included only 25 patients. 2) Owing to the retrospective study design, patients who received other treatment were not included for comparison, and the study lacks randomization. Although this was a small-scale study, it is reasonable to conclude that the results of this study would be meaningful because this is the first case-control study to investigate this subject. Large-scale prospective controlled studies are warranted for accurate intergroup comparisons between the aforementioned patient groups to draw definitive conclusions.

\section{CONCLUSION}

Laboratory and radiographic findings, as well as clinical outcomes did not significantly differ between group 1 (patients who underwent autogenous bone grafting) and group 2 (patients who underwent metal cage implantation with allogenic bone grafting). Group 2 patients showed lower VAS scores than group 1 patients 1 month postoperatively. Therefore, it is reasonable to conclude that the use of a metal cage with allogenic bone grafts could offer the advantage of eliminating bone harvest site pain associated with autogenous bone 
grafting. Although the use of a metal cage with allogenic bone grafts for anterior column reconstruction remains controversial, our results suggest that it can be considered as an effective treatment of option for anterior column reconstruction in patients with infectious spondylitis.

\section{CONFLICTS OF INTEREST}

No potential conflict of interest relevant to this article was reported.

\section{INFORMED CONSENT}

Informed consent was obtained from all individual participants included in this study.

\section{AUTHOR CONTRIBUTIONS}

\author{
Conceptualization : JRC \\ Data curation : IYH \\ Formal analysis : SHK \\ Methodology : JRC \\ Project administration : IYH \\ Visualization : SHK \\ Writing - original draft : IYH, HYC \\ Writing - review \& editing : IYH, HYC
}

\section{ORCID}

Jae-Ryong Cha https://orcid.org/0000-0001-6646-0534

Il-Yeong Hwang https://orcid.org/0000-0002-6143-4633

Sun-Hwan Kwon https://orcid.org/0000-0002-7198-4970

Hee-Yoon Chung https://orcid.org/0000-0002-0019-4947

\section{- Acknowledgements}

This study was performed at Ulsan University Hospital, University of Ulsan College of Medicine.

\section{References}

1. An HS, Seldomridge JA : Spinal infections: diagnostic tests and imaging studies. Clin Orthop Relat Res 444 : 27-33, 2006

2. Cheung WY, Luk KD : Pyogenic spondylitis. Int Orthop 36 : 397-404, 2012

3. Collis JS : Total disc replacement: a modified posterior lumbar interbody fusion. Report of 750 cases. Clin Orthop Relat Res 193 : 64-67, 1985

4. Cottle L, Riordan T : Infectious spondylodiscitis. J Infect 56 : 401-412, 2008

5. Fernyhough JC, Schimandle JJ, Weigel MC, Edwards CC, Levine AM : Chronic donor site pain complicating bone graft harvesting from the posterior iliac crest for spinal fusion. Spine (Phila Pa 1976) 17 : 14741480, 1992

6. Frankel HL, Hancock DO, Hyslop G, Melzak J, Michaelis LS, Ungar GH, et al. : The value of postural reduction in the initial management of closed injuries of the spine with paraplegia and tetraplegia. I. Paraplegia 7 : 179-192, 1969

7. Jin D, Qu D, Chen J, Zhang H : One-stage anterior interbody autografting and instrumentation in primary surgical management of thoracolumbar spinal tuberculosis. Eur Spine J 13 : 114-121, 2004

8. Karadimas EJ, Bunger C, Lindblad BE, Hansen ES, Høy K, Helmig P, et al. : Spondylodiscitis. A retrospective study of 163 patients. Acta Orthop 79 : 650-659, 2008

9. Korovessis P, Vardakastanis K, Fennema P, Syrimbeis V : Mesh cage for treatment of hematogenous spondylitis and spondylodiskitis. How safe and successful is its use in acute and chronic complicated cases? A systematic review of literature over a decade. Eur J Orthop Surg Traumatol $26: 753-761,2016$

10. Kurz LT, Garfin SR, Booth RE Jr : Harvesting autogenous iliac bone grafts. A review of complications and techniques. Spine (Phila Pa 1976) 14 : 1324-1331, 1989

11. Linhardt O, Matussek J, Refior HJ, Krödel A : Long-term results of ventro-dorsal versus ventral instrumentation fusion in the treatment of spondylitis. Int Orthop 31 : 113-119, 2007

12. McCormack HM, Horne DJ, Sheather $S$ : Clinical applications of visual analogue scales: a critical review. Psychol Med 18 : 1007-1019, 1988

13. Park KH, Cho OH, Lee YM, Moon C, Park SY, Moon SM, et al. : Therapeutic outcomes of hematogenous vertebral osteomyelitis with instrumented surgery. Clin Infect Dis 60 : 1330-1338, 2015

14. Przybylski GJ, Sharan AD : Single-stage autogenous bone grafting and internal fixation in the surgical management of pyogenic discitis and vertebral osteomyelitis. J Neurosurg 94 : 1-7, 2001

15. Rezai AR, Woo HH, Errico TJ, Cooper PR : Contemporary management of spinal osteomyelitis. Neurosurgery 44 : 1018-1025, 1999

16. Robinson Y, Tschoeke SK, Finke T, Kayser R, Ertel W, Heyde CE : Successful treatment of spondylodiscitis using titanium cages: a 3-year followup of 22 consecutive patients. Acta Orthop 79 : 660-664, 2008

17. Sawin PD, Traynelis VC, Menezes AH : A comparative analysis of fusion rates and donor-site morbidity for autogeneic rib and iliac crest bone 
Reconstruction of Infectious Spondylitis | Cha JR, et al.

grafts in posterior cervical fusions. J Neurosurg $88: 255-265,1998$

18. Schnee CL, Freese A, Weil RJ, Marcotte PJ : Analysis of harvest morbidity and radiographic outcome using autograft for anterior cervical fusion. Spine (Phila Pa 1976) 22 : 2222-2227, 1997

19. Shetty AP, Aiyer SN, Kanna RM, Maheswaran A, Rajasekaran S : Pyogenic lumbar spondylodiscitis treated with transforaminal lumbar interbody fusion: safety and outcomes. Int Orthop 40 : 1163-1170, 2016

20. Summers $B N$, Eisenstein $S M$ : Donor site pain from the ilium. A complication of lumbar spine fusion. J Bone Joint Surg Br 71 : 677-680, 1989

21. Talia AJ, Wong ML, Lau HC, Kaye AH : Safety of instrumentation and fusion at the time of surgical debridement for spinal infection. J Clin Neurosci 22 : 1111-1116, 2015

22. Tan GH, Goss BG, Thorpe PJ, Williams RP : CT-based classification of long spinal allograft fusion. Eur Spine J 16 : 1875-1881, 2007
23. Yang SC, Chen HS, Kao YH, Tu YK : Single-stage anterior debridement and reconstruction with tantalum mesh cage for complicated infectious spondylitis. World J Orthop 8 : 710-718, 2017

24. Younger EM, Chapman MW : Morbidity at bone graft donor sites. J Orthop Trauma 3 : 192-195, 1989

25. Zhang H, Zeng K, Yin X, Huang J, Tang M, Guo C : Debridement, internal fixation, and reconstruction using titanium mesh for the surgical treatment of thoracic and lumbar spinal tuberculosis via a posterior-only approach: a 4-year follow-up of 28 patients. J Orthop Surg Res 10 : 150, 2015

26. Zhang ZX, Li T, Hao DJ : Single-stage treatment of osteomyelitis of the cervical spine using anterior instrumentation and titanium mesh cages. Spine (Phila Pa 1976) 41 : E949-E954, 2016 